of the two retrieved implants were similar to those previously reported in the literature (Bauer et al 1991; Furlong and Osborn 1991: Hardy et al 1991). The distal part of the prosthesis, which is polished and does not have an HA coating, was not attached to the bone.

Although the migration rates of these two particular prostheses were not measured by the methods described in our recent paper, the radiographs suggest that they were behaving in an entirely similar way to those which we described. We conclude that the histological appearances around the two retrieved prostheses can be correlated with the migration behaviour as described by us.

M. A. R. FREEMAN, MD, FRCS

Bone and Joint Research Unit

Royal London Hospital Medical College

London.

Bauer TW, Geesink RCT, Zimmerman R, McMahon JT. Hydroxyapatite-coated femoral stems: histological analysis of components retrieved at autopsy. J Bone Joint Surg [Am] 1991;73-A: 1439-52.

Furlong RJ, Osborn JF. Fixation of hip prostheses by hydroxyapatite coatings. J Bone Joint Surg [Br] 1991;73-B:741-5.

Hardy DCR, Frayssinet P, Guilhem A, Lafontaine MA, Delince P. Bonding of hydroxyapatite-coated femoral prostheses: histopathology of specimens from four cases. J Bone Joint Surg [Br] $1991 ; 73-\mathrm{B}: 732-40$.

Kroon P-O, Freeman MAR. Hydroxyapatite coating of hip prostheses: effect on migration into the femur. $J$ Bone Joint Surg [Br] 1992;74-B:518-22.

\section{IONISING RADIATION AND THE ORTHOPAEDIC SURGEON}

Sir,

The publication of the editorial 'Ionising radiation and the orthopaedic surgeon' by Hynes et al $(1992 ; 74-B: 332-4)$ in a leading orthopaedic journal is both timely and a cause for congratulation. I was astonished, however, to find that the authors had written their editorial with no reference to clinical radiologists or departments of radiology and with only a brief mention of the existence of a radiographer. In Europe we are all subject to both the EEC and international regulations which require that every unit or hospital with a Department of Clinical Radiology has an appointed Radiation Protection Adviser (RPA) who is a physicist with an interest in this field. In the UK the head of the Department of Radiology, who is a radiologist, is responsible to the Health Authority for the implementation of radiation protection requirements for both staff and patients; this includes the use of radiological equipment outside the main department, such as in the operating theatre, and the administration of radioactive substances outside the department as in the wards.

A Radiation Protection Supervisor (RPS), usually a senior radiographer, is appointed in every hospital using radiation. When difficulties in securing compliance are encountered, the RPS reports unsatisfactory practices to the head of the Department of Clinical Radiology.

In addition, most hospitals have a Radiation Protection Committee to assist in the implementation of advice and it is usual for the RPA and RPS to attend their meetings. All these elements of radiation protection have been in place for many years. They have evolved to take into account changed practices and new equipment and to respond to advice from the National Radiation Protection Board.

Finally, as the editorial almost completely restricted its comment to radiation hazards to clinical staff, it would have been better entitled 'Ionising radiation to the orthopaedic surgeon'. It goes without saying that there are many other aspects of reduction of radiation that should be of concern to the orthopaedic surgeon.

\section{J. STOKER, FRCP, FRCR, FRCS}

Director of Clinical Radiology

The Institute of Orthopaedics

Royal National Orthopaedic Hospital

London.

Hynes DE, Conere T, Mee MB, Cashman WF. Editorial: Ionising radiation and the orthopaedic surgeon. $J$ Bone Joint Surg [Br] 1992;74-B:332-4.

\section{THIGH PAIN AFTER HIP ARTHROPLASTY}

Sir,

We read with interest the article entitled 'Thigh pain after cementless hip arthroplasty' by Campbell et al in the January 1992 issue (1992;74-B:63-6). We would like to inform both the authors of this paper and other readers of the incidence of this symptom in the Mittelmeier ceramic cementless hip arthroplasty.

We have reviewed 94 hips with this arthroplasty at a mean of six years (four to 12) after operation. Our incidence $(19 \%)$ and type of start-up thigh pain were similar to those reported by Campbell et al. We found a strong correlation with femoral fit ( $\mathrm{p}<0.01$ ) but no relation to sex, subsidence, periosteal reaction or pedestal formation (Choudhry 1990). Campbell et al make no reference to the pedestal sign (Mittelmeier 1984) at the tip of the prosthesis; we consider it to be a possible marker of distal load transfer which may be related to thigh pain.

We agree that thigh pain is not merely a fleeting symptom which settles with time. It may be that new designs of prosthesis, particularly those with proximal hydroxyapatite coating, will reduce the incidence of this troublesome symptom.

J. P. IVORY, MA, FRCS

R. R. CHOUDHRY, MCh(Orth)

T. F. STOYLE, FRĆS

Department of Orthopaedics

Glenfield General Hospital

Leicester.

Campbell ACL, Rorabeck CH, Bourne RB, Chess D, Nott L. Thigh pain after cementless hip arthroplasty: annoyance or ill omen. J Bone Joint Surg [Br] 1992;74-B:63-6.

Choudhry RR. Radiographic analysis of the Mittelmeier uncemented total hip replacement. MCh(Orth) Thesis, University of Liverpool, 1990.

Mittelmeier H. Total hip replacement with the Autophor cementfree ceramic prosthesis. In: Morscher E, ed. Cementless fixation of hip endoprosthesis. Berlin, etc: Springer Verlag, 1984:225-41.

\section{TEST FOR CALCANEAL TENDON RUPTURE}

Sir,

We enjoyed reading the brief report by Scott and Al Chalabi on 'How the Simmonds-Thompson test works' in your March 1992 issue $(1992 ; 74-B: 314-5)$ but we object to the conclusions. The authors consider that the test mainly reflects the integrity of the soleus musculotendinous unit. We believe that it is simply one example of the squeeze test (Lister 1984), which can be demonstrated in any intact musculotendinous unit. In cadaver specimens we have shown that the response, measured in degrees of plantar flexion, was the same regardless of the integrity of the soleus tendon, 
but that it was decreased when the fascial envelope of the calf muscles was opened.

We have observed that the Simmonds-Thompson test may not return to normal, when compared with the opposite intact side, after the successful open repair of a calcaneal tendon rupture. We believe that the opening of the fascial envelope contributes to this loss, in addition to the effect of adhesions and muscle wasting, and conclude that although soleus may contribute to the test it is not the principal element.

O. P. LAHOTI, MS (Orth), FRCS I

D. MCCORMACK, MB, BSc, FRCS I

Department of Orthopaedic Surgery

Meath Hospital

Dublin 8

Ireland.

Lister G. The hand, diagnosis and indications Second edition. Edinburgh, etc: Churchill Livingstone, 1984:27.

Scott BW, Al Chalabi A. How the Simmonds-Thompson test works. J Bone Joint Surg [Br] 1992;74-B:314-5.

\section{Reply from one of the authors:}

Sir,

To describe the Simmonds-Thompson test as simply an example of the squeeze test oversimplifies the matter. Our ultrasound findings showed differential longitudinal movement of the soleus and gastrocnemius, indicating a relatively complex sequence of mechanical events. I have read the first edition of Lister's book; the test was described with reference to the forearm, but I could not find an explanation of its mechanics.

The comments regarding the integrity of the fascial envelope were interesting. We did not investigate this aspect. Rupture of the fascia over the muscle belly might make posterior bulging of the soleus less prominent and therefore diminish ankle movement, but the other explanations, namely postinjury adhesions and muscle wasting, are more likely to reduce ankle movement. It is also unlikely that a calcaneal tendon injury would be associated with injury to the muscle fascia.

Our findings in fresh amputation specimens differed. We defend our conclusions, which agree with those of Thompson himself (1962).

\section{B. W. SCOTT, FRCS}

Department of Orthopaedic Surgery

Sheffield Children's Hospital

Sheffield.

Thompson TC, Doherty JH. Spontaneous rupture of tendon of Achilles: a new clinical diagnostic test. $J$ Trauma 1962;2: 126-9. 